\section{КОРРЕКЦИЯ МЕСТНОГО}

\section{ИММУНИТЕТА У ПАЦИЕНТОВ \\ С ВОСПАЛИТЕАЬНО- \\ АЕСТРУКТИВНЫМИ \\ ЗАБОАЕВАНИЯМИ ПОАОСТИ РТА}

Высокий эффект защиты полости рта обеспечивает иммунная система, включающая специфические и неспецифические, клеточные и гуморальные факторы, которые функционируют в тесной взаимосвязи $[2,3]$.

Многочисленными исследованиями установлено, что восстановление функциональной активности иммунной системы является непременным условием успеха комплексной терапии самых различных патологических состояний и заболеваний человека $[4,6]$.

Хронический рецидивирующий афтозный стоматит (XРАC) и плоский лишай (ПЛ) являются воспалительными заболеваниями и характеризуются пониженной иммунологической реактивностью и нарушениями неспецифической защиты $[1,5,8]$. Анализ иммунологических показателей слюны у больных ХРАС позволил выявить значительное снижение активности показателей гуморального и местного иммунитета в смешанной нестимулированной слюне в $85,7 \%$ случаев. Установлено достоверное снижение в слюне уровня $\operatorname{IgA}$ в 2,2 раза и особенно секреторного IgA - в 2,7 раза. Показано, что у больных XРAC значительно снижается и функция неспецифической защиты слюны, что проявлялось в снижении ее лизоцимной активности в среднем в 1,9 раза [7]. Исследования иммунологических показателей крови при ПЛ, проводимые Рабиновичем О.Ф. (2005) и Спицыной В.И. (2002), демонстрируют прямо противоположные результаты. По данным Рабиновича О.Ф., уровень иммуноглобулина $\mathrm{G}$, М и А в сыворотке крови увеличивался в разной степени при различных формах заболевания. По результатам Спицыной В.И., уровень иммуноглобулина А понижался в разной степени у всех больных с красным плоским лишаем; а количественные показатели иммуноглобулина $\mathrm{G}$ и $\mathrm{M}$ были различными - в отдельных случаях наблюдалось их повышение, в других - понижение.

С целью коррекции иммунодефицитных состояний сегодня используются лекарственные сред-

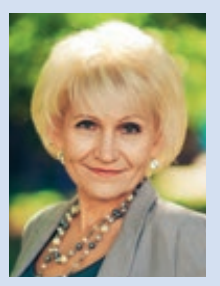

Токмакова С.И. профессор, д.м.н., зав. кафедрой терапевтической стоматологии ГБОУ ВПО АГМУ, г. Барнаул

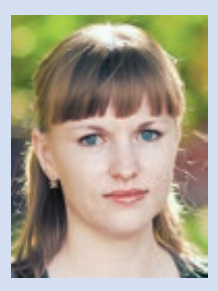

Луницына Ю.В. к.м.Н., ассистент кафедры терапевтической стоматологии ГБОУ ВПО АГМУ, г. Барнаул, lunizyna.julja@mail.ru

\section{Резюме}

Целью проведенного исследования явилась оценка влияния средства для полости рта на основе пантогематогена и бадана на факторы местного иммунитета полости рта в группе здоровых лиц, у пациентов с афтозным стоматитом и плоским лишаем. Выявлено, что во всех группах наблюдения после курсового применения средства происходит повышение значений целого ряда показателей местного клеточного и гуморального иммунитета.

Ключевые слова: факторы местного иммунитета, полость рта, афтозный стоматит, плоский лишай.

CORRECTION OF LOCAL IMMUNITY AT PATIENTS WITH INFLAMMATORY AND DESTRUCTIVE DISEASES OF ORAL CAVITY

Tokmakova S.I., Lunitsyna J.V.

\section{The summary}

The purpose of the conducted research was the assessment of influence of means for an oral cavity on a basis pantogematogena and a bergenia on factors of local immunity of an oral cavity in group of healthy faces, at patients with aftosa stomatitis and lichen planus. It is revealed that in all groups of supervision after course application of means there is an increase of values of a number of indicators of local cellular and humoral immunity.

Keywords: factors of local immunity, oral cavity, aftosa stomatitis, lichen planus. 
ства как синтетического, так и природного происхождения. Растительные средства, в отличие от синтетических, имеют ряд преимуществ: мягкое иммуномодулирующее действие, низкую токсичность, активацию функций не только иммунной, но и нервной и эндокринной систем благодаря наличию комплекса биологически активных веществ, оказывающих воздействие на организм в целом.

\section{Цель исследования}

Оценить влияние средства для полости рта на основе пантогематогена и бадана на факторы местного иммунитета полости рта в группе здоровых лиц и у пациентов с ХРАС и ПЛ.

\section{Задачи исследования:}

1) изучение влияния курсового применения средства для полости рта на основе пантогематогена и бадана в группе здоровых лиц, у пациентов с ХРАС и ПЛ на факторы клеточного звена местной резистентности полости рта: фагоцитарную активность нейтрофильных гранулоцитов слюны, кислородзависимую бактерицидность нейтрофилов слюны; 2) оценка влияния курсового применения средства для полости рта на основе пантогематогена и бадана в группе здоровых лиц, у пациентов с ХРАС и ПЛ на гуморальное звено иммунитета с помощью определения уровня секреторного иммуноглобулина A (s-Ig A) в слюне.

\section{Материал и методы исследования}

Для достижения поставленной цели и решения задач исследования нами было обследовано 72 человека. Среди них здоровые лица - 25 человек, пациенты с заболеваниями слизистой оболочки полости рта (СОПР) - 47 человек. Группу здоровых составили 6 мужчин $(24 \%)$ и 19 женщин

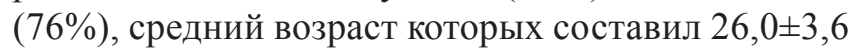
года. Среди больных с воспалительно-деструктивными заболеваниями было выделено две группы: пациенты с хроническим рецидивирующим афтозным стоматитом (XPAC) и с эрозивноязвенной формой плоского лишая (ПЛ). Больные с ХРАС - 23 человека. Сформированную группу составили 8 мужчин (34,8\%) и 15 женщин $(65,2 \%)$, средний возраст которых $33,7 \pm 10,4$ года. Больные с ПЛ - 24 человека. Сформированную группу составили 7 мужчин (29,2\%) и 17 женщин (70,8\%), средний возраст которых 50,3土8,1 года.

Средство для полости рта на основе пантогематогена и бадана представляет собой растворимый в воде порошок светло-коричневого цвета в капсулах для приготовления раствора. Состав одной капсулы препарата включает 100 мг пантогематогена сухого и 400 мг сухого экстракта бадана. Средство назначали в виде ротовых ванночек 3 раза в день: утром, в обед и вечером после еды и чистки зубов. Содержимое одной капсулы настаивали 2-3 часа в теплой кипяченой воде (200 мл). После процедуры в течение 1-2 часов исключали прием жидкой и твердой пищи. Курс применения составлял 20 дней.

Для оценки местного иммунитета полости рта у здоровых лиц, а также у пациентов с ХРАC изучали динамику показателей иммунной защиты. Материалом для исследования являлась нестимулированная слюна, которая собиралась натощак после полоскания полости рта физиологическим раствором. Оценку функциональной активности нейтрофильных гранулоцитов в слюне (НСТ-тест) осуществляли в модификации М.А. Темирбаева (1991) восстановлением нитросинего тетразолия, кроме того, определяли фагоцитарный индекс (ФИ). Было проанализировано соотношение значений показателей спонтанного и стимулированного НСТ-теста с вычислением следующих коэффициентов: а) отношение стимулированного НСТ-теста к спонтанному с выведением коэффициента мобилизации (КМ) нейтрофильных гранулоцитов; б) резервную реактивность нейтрофилов (РАН) по формуле: НСТ-тест (стимулированный) - НСТ-тест (спонтанный).

Определение s-Ig А выполнялось иммуноферментным методом с использованием коммерческого набора s-IgA-ИФА-БЕСТ ЗАО «Вектор-Бест» (г.Новосибирск). Концентрацию s-Ig А выражали в мг/л.

Исследование проводили три раза: до начала лечения, после курса лечения и через 1 месяц после его окончания.

Методы статистической обработки. Статистическую обработку проводили при помощи пакета прикладных статистических программ. Статистический анализ включал расчет средней арифметической (М), ошибки средней арифметической (m) и вероятности различий $(\mathrm{P})$. Достоверность различий определяли с помощью критерия Стьюдента (t) для независимых выборок. Различия оценивали как значимые при $\mathrm{p}<0,05$.

\section{Результаты иммунологического исследования}

Результаты исследований показали, что применение средства на основе пантогематогена и бадана в виде ротовых ванночек в группе здоровых лиц приводит к повышению иммунологических показателей: ФИ - на $7 \%(\mathrm{p}<0,05)$, стимулированного НСТ-теста - на $20 \%(\mathrm{p}>0,05)$, РАН - на $60 \%(\mathrm{p}<0,05)$ 
(табл. 1). Это свидетельствует об активации функциональной фагоцитарной активности, кислородзависимой бактерицидной функции и цитотоксического потенциала нейтрофильных гранулоцитов в полости рта, то есть усилении функциональной активности клеточного звена иммунитета полости рта. Повышение уровня s-Ig А в ротовой жидкости после курса в 1,5 раза (табл. 1) свидетельствует об усилении резистентности слизистой оболочки, функциональной активности гуморального звена иммунитета полости рта под иммуностимулирующим действием.

Таблица 1

Динамика изучаемых параметров в группе здоровых лиц на фоне применения средства на основе пантогематогена и бадана, $\mathrm{M \pm m}$

\begin{tabular}{|c|c|c|c|}
\hline $\begin{array}{c}\text { Изучаемый } \\
\text { параметр }\end{array}$ & $\begin{array}{c}\text { До курса } \\
\text { применения }\end{array}$ & $\begin{array}{c}\text { После курса } \\
\text { применения }\end{array}$ & через 1 месяи \\
\hline ФИ, \% & $63,36 \pm 7,34$ & $70,2 \pm 8,77^{*}$ & $68,36 \pm 10,18$ \\
\hline $\begin{array}{c}\text { НСТ-тест } \\
\text { спонт., у.е. }\end{array}$ & $0,66 \pm 0,42$ & $0,61 \pm 0,19$ & $0,65 \pm 0,27$ \\
\hline $\begin{array}{c}\text { НСТ-тест } \\
\text { стимул., у.е. }\end{array}$ & $0,81 \pm 0,40$ & $1,0 \pm 0,22$ & $1,13 \pm 0,25^{*}$ \\
\hline КМ, у.е. & $1,48 \pm 0,87$ & $1,69 \pm 0,39$ & $2,07 \pm 0,74^{*}$ \\
\hline РАН, у.е. & $0,15 \pm 0,07$ & $0,39 \pm 0,18^{*}$ & $0,49 \pm 0,18^{*}$ \\
\hline s-ІІ А, мг/л & $482,13 \pm 146,12$ & $561,86 \pm 127,42$ & $756,29 \pm 114,25^{* 0}$ \\
\hline
\end{tabular}

* отличие при сравнении с показателями до курса применения статистически значимо $(p<0,05)$; ${ }^{\circ}$ отличие при сравнении с показателями после курса применения статистически значимо $(p<0,001)$

Исследование состояния местного иммунитета полости рта у пациентов с ХРАС и ПЛ выявило, что до начала лечебных мероприятий у больных все показатели были снижены по сравнению с показателями в группе здоровых лиц (табл. 2, 3).

К концу курса применения средства на основе пантогематогена и бадана у больных отмечалось увеличение показателей ФИ, спонтанного и стимулированного НСТ-теста, а еще через месяц они приближались к уровню нормы, значимо отличаясь от исходного уровня (табл. 2, 3). Это свидетельствует об активации клеточного звена местного иммунитета под влиянием препарата.

Изучение влияния проводимого лечения на гуморальное звено местного иммунитета полости рта у больных с ХРАС и ПЛ выявило, что после 3-недельного курса применения средства концентрация s-IgA в ротовой жидкости статистически значимо повышалась. Тенденция к увеличению изучаемого параметра сохранялась и через 1 месяц после лечения (рис. 1).
Таблиия 2

Динамика показателей клеточного звена местного иммунитета полости рта у пациентов с ХРАС на фоне применения средства на основе пантогематогена и бадана $(\mathrm{M} \pm \mathrm{m})$

\begin{tabular}{|c|c|c|c|}
\hline $\begin{array}{c}\text { Изучаемый } \\
\text { параметр }\end{array}$ & $\begin{array}{c}\text { До курса } \\
\text { применения }\end{array}$ & $\begin{array}{c}\text { После курса } \\
\text { применения }\end{array}$ & $\begin{array}{c}\text { Через 1 месяи } \\
\text { после окончания } \\
\text { курса }\end{array}$ \\
\hline ФИ, \% & $56,28 \pm 4,23$ & $\begin{array}{c}66,44 \pm 4,34 \\
\mathrm{P} 1^{*} \mathrm{P} 3^{*}\end{array}$ & $\begin{array}{c}72,72 \pm 4,04 \\
\mathrm{P} 1^{*} \mathrm{P} 2^{*}\end{array}$ \\
\hline $\begin{array}{c}\text { HСТ-тест } \\
\text { спонт. - у.е. }\end{array}$ & $0,32 \pm 0,12$ & $0,61 \pm 0,37 \mathrm{P} 1^{* *}$ & $0,62 \pm 0,22 \mathrm{P} 1^{* *}$ \\
\hline $\begin{array}{c}\text { HСТ-тест } \\
\text { стимул. - у.е. }\end{array}$ & $0,43 \pm 0,15$ & $0,75 \pm 0,31 \mathrm{P} 1^{* *}$ & $\begin{array}{c}1,05 \pm 0,23 \mathrm{P} 1^{* *} \\
\mathrm{P} 2^{* *}\end{array}$ \\
\hline КМ (у.е.) & $1,39 \pm 0,26$ & $1,54 \pm 1,0 \mathrm{P} 1^{*}$ & $\begin{array}{c}1,75 \pm 0,38 \mathrm{P}^{* *} \\
\mathrm{P} 2^{*}\end{array}$ \\
\hline РАН (у.е.) & $0,11 \pm 0,07$ & $0,14 \pm 0,03$ & $\begin{array}{c}0,43 \pm 0,17 \mathrm{P} 1^{* *}, \\
\mathrm{P} 2^{* *}\end{array}$ \\
\hline
\end{tabular}

Примечание:

P1 - различие с уровнем показателя до лечения статистически значимо * $p<0,05 ; * * p<0,001 ; P 2-$ различие с уровнем показателя после лечения статистически значимо * $p<0,05$; $* * p<0,001$.

Таблица 3

Динамика показателей клеточного звена местного иммунитета полости рта у пациентов с ПЛ на фоне применения пантомарина, $\mathrm{n}=24$ ( $\mathrm{M \pm m}$ )

\begin{tabular}{|c|c|c|c|}
\hline $\begin{array}{c}\text { Изучаемый } \\
\text { параметр }\end{array}$ & $\begin{array}{c}\text { До курса } \\
\text { применения }\end{array}$ & $\begin{array}{c}\text { После курса } \\
\text { применения }\end{array}$ & $\begin{array}{c}\text { Через 1 месяи } \\
\text { после окончания } \\
\text { курса }\end{array}$ \\
\hline ФИ, \% & $57,25 \pm 2,67$ & $\begin{array}{c}60,31 \pm 3,55 \\
\mathrm{P} 1^{*}\end{array}$ & $\begin{array}{c}63,06 \pm 2,62 \\
\mathrm{P} 1^{*} \mathrm{P} 2^{*}\end{array}$ \\
\hline $\begin{array}{c}\text { НСТ-тест спонт. } \\
\text { - у.е. }\end{array}$ & $0,42 \pm 0,14$ & $\begin{array}{c}0,63 \pm 0,39 \\
\mathrm{P} 1^{*}\end{array}$ & $\begin{array}{c}0,61 \pm 0,22 \\
\mathrm{P} 1^{*}\end{array}$ \\
\hline $\begin{array}{c}\text { НСТ-тест } \\
\text { стимул. -у.е. }\end{array}$ & $0,57 \pm 0,22$ & $\begin{array}{c}0,77 \pm 0,38 \\
\mathrm{P} 1^{*}\end{array}$ & $\begin{array}{c}0,99 \pm 0,24 \\
\mathrm{P} 1^{* *}, \mathrm{P} 2^{*}\end{array}$ \\
\hline КМ (у.е.) & $1,4 \pm 0,32$ & $1,56 \pm 1,05$ & $\begin{array}{c}1,68 \pm 0,4 \\
\mathrm{P}^{*}\end{array}$ \\
\hline РАН (у.е.) & $0,15 \pm 0,13$ & $0,14 \pm 0,03$ & $\begin{array}{c}0,38 \pm 0,18 \\
\mathrm{P}^{* *}, \mathrm{P}^{* *}\end{array}$ \\
\hline
\end{tabular}

Примечание:

P1 - различие с уровнем показателя до лечения статистически значимо * $p<0,05 ; * * p<0,001 ;$; 2 - различие с уровнем показателя после лечения статистически значимо $* p<0,05 ; * * p<0,001$. 


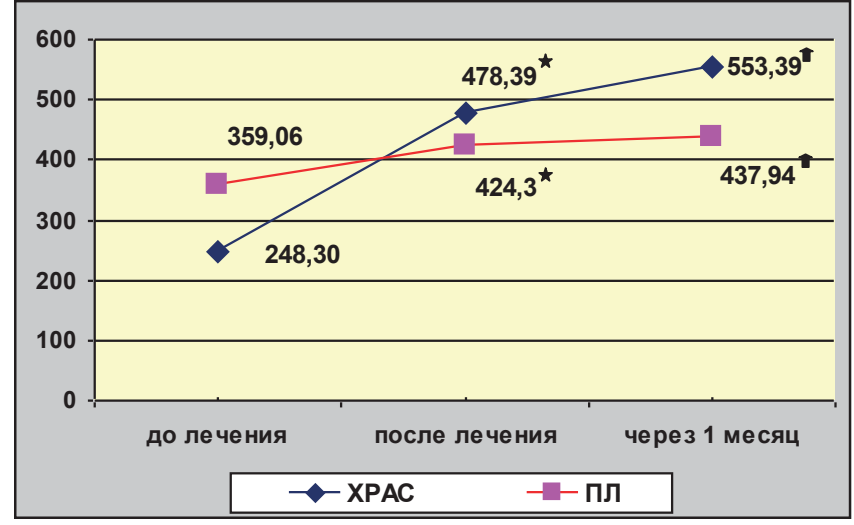

Рис. 1. Динамика уровня секреторного Ig А у пациентов с воспалительно-деструктивными процессами

^ различие с уровнем показателя до лечения внутри группы статистически значимо, $\mathrm{p}<0,05$;

- различие с уровнем показателя после лечения внутри группы статистически значимо, $p<0,05$

Изучение влияния проводимого лечения на гуморальное звено местного иммунитета полости рта у больных воспалительно-деструктивными процессами выявило, что после 3-недельного курса применения пантомарина концентрация s-Ig А в ротовой жидкости статистически значимо повышалась. Тенденция к увеличению изучаемого параметра сохранялась и через 1 месяц после лечения (рис. 1).

\section{Выводы}

После применения средства для полости рта на основе пантогематогена и бадана в виде ротовых ванночек в исследуемых группах имело место достоверное повышение значений целого ряда показателей: ФИ, значений стимулированного и спонтанного НСТ-теста, РАН, КМ. Это свидетельствует об активации функциональной (фагоцитарной) активности нейтрофильных гранулоцитов в полости рта, то есть усилении функциональной активности клеточного звена иммунитета полости рта.

Достоверное повышение уровня s-Ig А в ротовой жидкости после курса применения средства свидетельствует об усилении функциональной активности гуморального звена местного иммунитета полости рта.

\section{Заключение}

Таким образом, под влиянием средства для полости рта на основе пантогематогена и бадана происходит нормализация показателей местного иммунитета полости рта. В первую очередь отмечается повышение активности клеточного звена иммунитета, что имеет большое значение для течения хронических воспалительных заболеваний.

\section{ЛИТЕРАТУРА}

1. Алиев М.М. Иммунологическая реактивность слюны и крови у больных язвенным стоматитом / М.М.Алиев, Л.М.Ахмедова, Ф.Ю.Кулиев // Аллергология и иммунология. - 2000. - Т. 1. - №2. - С. 140.

2. Борисова О.В. Состояние иммунитета и коррекция его нарушений у больных с заболеваниями слизистой оболочки полости рта и пародонта / О.В.Борисова, М.М.Прудникова, 0.И.Щербаченко // Тезисы 2-го Международного конгресса по иммунологии и иммунореабилитации. - Анталия (Турция). - 1996. -105 c.

3. Борисова О.В. Применение плазмофереза в лечении рецидивирующего афтозного стоматита / О.В.Борисова, Н.Л.Елькова, М.М.Прудникова // Стоматология. - 1997. т.76. - №3. - С. 23-25.

4. Дмитриева Л.А. Разработка комплексных индивидуальных методов лечения заболеваний слизистой оболочки полости рта в зависимости от иммунологического статуса пациента / Л.А. Дмитриева. - Москва, 2001. - 135 с.

5. Дроботько Л.Н. Хронический рецидивирующий афтозный стоматит / Л.Н.Дроботько, С.Ю.Страхова // Российский медицинский журнал. - 2006. - №29. - С. 2096-2098.

6. Елькова Н.Л. Диагностика и лечение тяжелых стоматологических заболеваний на основе статистических методов и оценки иммунного статуса / Н.Л.Елькова // Актуальные вопросы высшего образования, теории и практики современной стоматологии: сб. науч. тр. - Воронеж, 2002. C. 65-69.

7. Ионов В.В. Состояние местного иммунитета, свободнорадикальных процессов и антиоксидантной защиты в слюне при хроническом рецидивирующем афтозном стоматите / Автореферат диссертации на соискание ученой степени кандидата медицинских наук, Москва, 2008. - 27 с.

8. Максимовская Л.Н. Клинико-иммунологические особенности течения рецидивирующего афтозного стоматита / Л.Н.Максимовская, В.Н.Царев // Стоматология. - Москва, 1995. - №1. - C.16.

9. Рабинович О.Ф. Методы диагностики и местного лечения заболеваний слизистой оболочки полости рта (красный плоский лишай, рецидивирующий афтозный стоматит, декубитальные язвы) / О.Ф.Рабинович, Е.Л.Эпельдимова // Стоматология. - 2005. - №3. - С. 58-63.

10. Спицына В.И. Патогенез иммунодефицита у больных красным плоским лишаем слизистой оболочки полости рта / В.И.Спицына // Российский стоматологический журнал. 2002. - №4. - С. 18-20. 